read for the first time very recently, were also named as having had a profound influence on an individual's way of thinking. Primo Levi's Survival in Auschwitz fit this category, as did Sohachi Yamaoka's 26-volume novel, Tokugawa Ieyasu. According to the professor of economics who selected the Japanese epic: "Compared to this major work of literature, Don Quixote and War and Peace are child's play."

Popular literature was also represented among the titles selected. Tom Clancy's The Hunt for Red October and Josephine Tey's The Daughter of Time were chosen as good recreational reading. A professor of industry and technology mentioned Ellis Peters' The Raven in the Foregate, confiding, "I save these until after grades are turned in each semester, then I go back in time to 12th-century England. Alternatively, I enjoy escaping into the 23d century with the Star Trek novels."

Such honest and provocative comments added life and warmth to our usually impersonal exhibit cases. So as not to lock up the library's copies of every work mentioned, we sought as many personal copies of books as possible. In this way, also, we collected quite a number of bright-colored paperbacks and books with dust jackets which helped to make the exhibit more attractive. Although some people were unwilling to part with their "favorite" books, even for a short time, most were very cooperative in lending materials for this project. Each book was exhibited with the individual's comments about it.

The exhibit was mounted in early December when students and faculty members, preoccupied by term papers and final exams, looked forward to vacation. Many who stopped to look at the exhibit commented that they were going to read a particular book over the holidays, when they would have time. In addition, the exhibit attracted the attention of the outside community when the local newspaper featured an article about it (complete with photograph) on the back page. We prepared a list of included titles which could be picked up by passersby near the exhibit cases.

Although library staff members did all of the typing and physical layout of the exhibit, this was a relatively easy project to coordinate. Aside from the initial distribution of the survey, no research was required; most of the text was prepared by the participants; and the materials exhibited were not limited to holdings within the library's collections.

While our primary goal in undertaking this project was to stimulate students' interest in books and reading, faculty enthusiasm for our plans was overwhelming. Those who participated encouraged their colleagues and students to visit the library, specifically to view the exhibit. Many who did not participate this time have asked when we are planning our next "My Favorite Book" exhibit. Others have suggested we poll students regarding their favorite books and one philosophy professor has already sent unsolicited information on his least favorite book.

Admittedly, we had asked a difficult, if not impossible, question. The comments we received, however, reflected the thoughtfulness with which people approached the assignment, sharing their feelings and personal experiences about something that was important and meaningful to them. What came through most clearly in the exhibit was the fact that books are much more than a means of transmitting information.

\title{
An automated finding aid for special collections
}

\author{
By Lucy Shelton Caswell \\ Curator \\ Library for Communication and Graphic Arts \\ Ohio State University
}

\author{
Karen A. Smith \\ Special Collections Cataloger \\ Library for Communication and Graphic Arts \\ Ohio State University
}

\section{and Hannah 'Thomas}

\author{
Manuscripts Cataloger \\ Library for Communication and Graphic Arts \\ Ohio State University
}

You may recognize this common reference desk scenario: The caller has an urgent request, "The song is from an old movie and I think the words are something like 'You must remember this, a kiss is still a kiss...' Do you have the sheet music?" An alternate scene: The researcher is preparing a book on the centennial of the Statue of Liberty. He asks to see all the editorial cartoons in the collection which depict this image. A third request: The professor stops by to say that her class needs to see several examples of historic photographs and she especially needs to have three or four cyanotypes on 


\section{ACQUISITION PERSPECTIVES}

1. ANY BOOK IN PRINT

means delivery to your library of all available books from any publisher or distributor in the U.S. or Canada. There is no list of publishers you must check ... WE DELIVER THEM ALL ... including trade, scientific/technical, text, university presses, paperbacks, associations, small presses, Canadian, and software.

Send us your direct orders and experience the "added value" received when using Book House.

\section{COMPLAH DATHAR}

\section{IN THE UNITHD STATES} AND CANADA

BOOK HOUSE

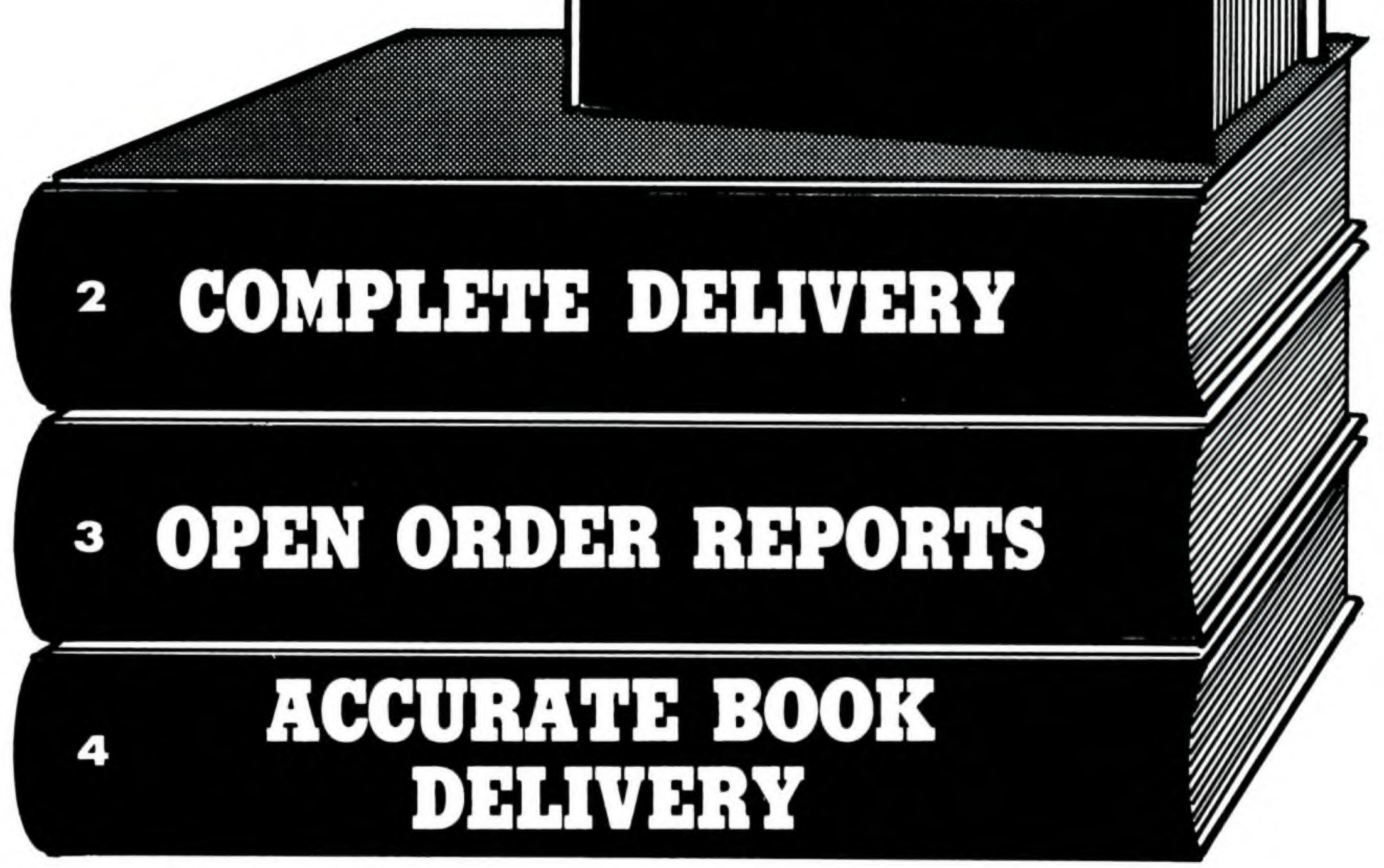

CALL TOLL-FREE TODAY

1-800-248-1146

In Canada \& Michigan

CALL COLLECT (517) 849-2117

OCLC Vendor No. 17397

SAN 169-3859

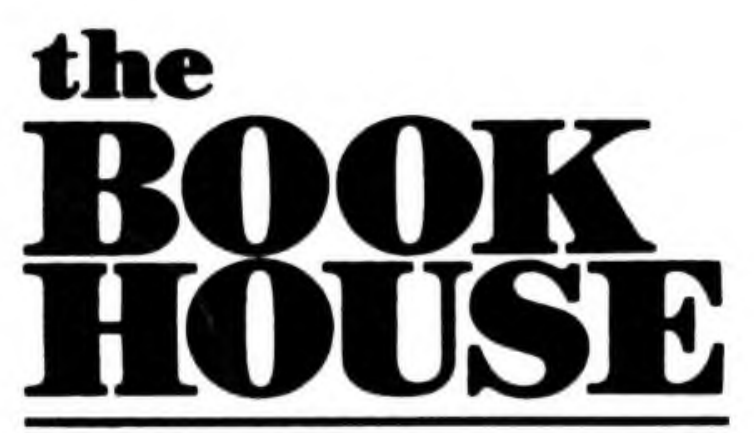

JOBBERS SERVING LIBRARIES WITH ANY BOOK IN PRINT SINCE 1962 208 WEST CHICAGO STREET JONESVILLE, MICHIGAN 49250 


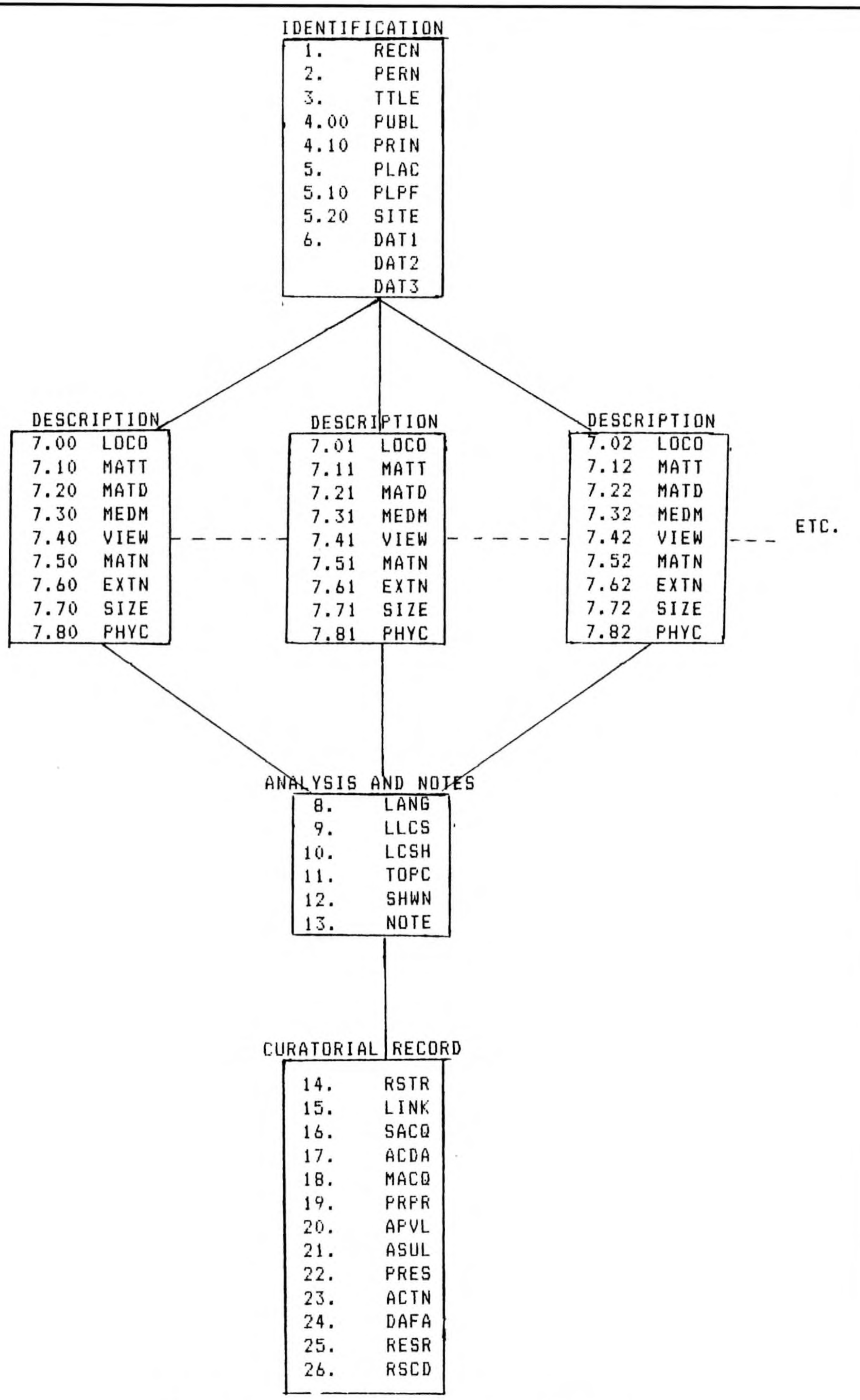

FIGURE 1. Scheme of general data entry form. 
view for her students to see. Or: A scholar from England needs to know the names of Jerome Lawrence's correspondents when the American Playwrights Theatre was established. How can these information needs be met?

Developing an automated finding aid to help libraries answer requests such as these is the challenge being undertaken at the Ohio State University Libraries (OSUL). While materials representative of other cultures and time periods are collected, four of the special collections and one of the departmental (branch) libraries at Ohio State have especially strong holdings of materials representative of several aspects of 19 th and 20thcentury American culture. They are located at different sites on the Columbus campus and each is charged with collecting in a separate area: American fiction, the theatre arts, music, and the graphic arts. All relate to the American experience, and the intellectual links between the collections are welldefined. In fact, one of the primary goals of the proposed database is to increase awareness of the inter-related nature of the special collections at the Ohio State University. The diverse physical locations of these special materials compound the traditional problems of organizing large collections of non-book materials to promote ready access to them for a broad range of scholarly purposes.

Work on creating an automated finding aid to solve these problems began in earnest early in 1987 , and a structure for the proposed database has been developed. The automated finding aid project (known as SCDB - the Special Collections Database $^{l}$ ) has the following goals:

1) Intellectual and physical control of the collections at the item level. What do we have and where is it?

2) Easy access to information about Ohio State's special collections by students and scholars, both locally and, potentially, nationally and internationally. How can we better inform current and potential researchers about the resources available at Ohio State?

3) Information for future collection development and management. How can the special collections at Ohio State grow to complement and enhance currently held materials and to fill gaps in present holdings?

Several assumptions have been made about SCDB as it relates to OSUL's online public access catalog and circulation system, the Library Control System (LCS), and OSUL contributions to the OCLC online union catalog. All books and serials in these collections are to be fully cataloged and, therefore, represented on LCS and OCLC. Collection level bibliographic records for discrete collections held by these special collections libraries

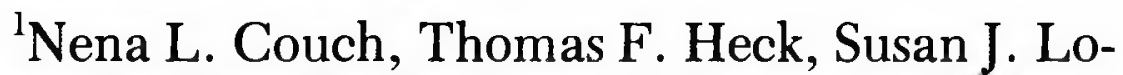
gan, Geoffrey D. Smith, and Robert A. Tibbetts are also in the working group which conceived and designed SCDB (Special Collections Database). (e.g., for the papers of Walt Kelly) will be created in the suitable MARC format and represented on LCS and OCLC. Where appropriate to meet local and/or national scholarly purposes, subcollection or item-level MARC records will also be created (e.g., for a daguerreotype self-portrait of Matthew Brady). All names used in SCDB will conform to conventions of the Anglo-American Cataloguing Rules, second edition, and will be verified against existing headings on LCS.

SCDB is intended to provide both item-level description of and varied means of access to materials through index fields in the database. For the purpose of SCDB, an item is one unit as defined by the person processing the collection and may vary from one motion picture lobby card to a folder of correspondence or a collection of drawings. SCDB is planned to improve upon the large number of typewritten finding aids (cards, notebooks, etc.) now available in these libraries and to provide a single information source for the content of these collections.

When discussing the design objectives of SCDB, ease of input and ease of retrieval of information were most important. Under the supervision of collection curators, advanced students or graduate associates will determine how to represent and input the data, so the number of fields had to be limited and format-specific data entry work forms developed. The current version of a scheme for general data description and analysis is shown in Figure 1 and an explanation of the field abbreviations shown in Figure 2.

A key feature of SCDB is the availability of nontraditional library access points, but it will not be necessary to describe each item using every field available on the data entry form. Many fields are to be repeatable, for example, the personal name/creator field, PERN, may contain several names and lifedates, qualified by relator codes to indicate persons associated with the item (such as the actors, producer, director and lighting designer for a given play). The relator codes to be linked with PERN have been adapted from the RBMS list of relator terms (CひRL News, October 1987, pp. 553-57). Similarly, TTLE functions to allow the title of the parent work or the first line of the verse of a song to be related to the item.

Three analytical fields have been created. TOPC may be used to indicate what the item is about: the cartoon is about the National Recovery Act, inflation, or Roosevelt's election to a fourth term. The LCSH field is provided for those times when one or more Library of Congress subject headings might be used. SHWN is to list what is depicted in graphic materials: Rudolph Valentino is on the poster; a snake is in the cartoon.

The designers of SCDB believe that access by type of material is also important, so the " 7 " fields were created. A second use for these fields is to describe components of an item (such as the case for a tintype). MATT will describe the general class or 
genre of an item (dance score, editorial cartoon, poster, etc.). MATD specifically describes the object at hand. (A comic strip might be in the form of an original drawing, proof, color guide proof, engraver's proof, proof on newsprint or tearsheet. A poster might be a one-sheet, three-sheet, lobby card or window card.) MEDM is to describe the format or technical process used for the object's creation. (The original cartoon mentioned above might be ink and crayon on coquille board.) VIEW will describe commonly used image categories (half-view portrait, landscape, etc.).

The library record section of the data entry form (fields 16-27) will be visible by password to staff only. The acquisition and disposition records are intended to give better custodial information about an item and to provide centralized online acquisition information (donor records).

There has been much discussion about the MARC mapability of SCDB and possible future methods of linking it to LCS. The data fields of SCDB are intended to follow consistent definitions and usage which would make mapping to MARC for descriptive purposes a viable option. Another possibility would be to use LCS as a gateway to provide more general access to the SCDB database.

\section{Descriptive fields}

$\begin{array}{lrl}\text { RECN } & 1.00 & \text { System-supplied record number (unique ID) } \\ \text { PERN } & 2.00 & \text { Personal name/creator, date and relator code } \\ \text { TTLE } & 3.00 & \text { Title and relator code } \\ \text { PUBL } & 4.00 & \text { Publisher } \\ \text { PRIN } & 4.10 & \text { Printer } \\ \text { PLAC } & 5.00 & \text { City/state/country of publication/printing } \\ \text { PLPF } & 5.10 & \text { City/state/country of performance } \\ \text { SITE } & 5.20 & \text { Site of performance } \\ \text { DAT1 } & 6.00 & \text { Date (year/month/day) of publication, creation, copyright, } \\ \text { DAT2 } & & \text { performance, etc., and relator code } \\ \text { DAT3 } & & \\ \text { LOCO } & 7.00 & \text { Location code } \\ \text { MATT } & 7.10 & \text { Type of material (general object class or genre) } \\ \text { MATD } & 7.20 & \text { Nature of materials (specific object descriptor) } \\ \text { MEDM } & 7.30 & \text { Medium (technical process and/or physical material) } \\ \text { VIEW } & 7.40 & \text { View category of visual images } \\ \text { MATN } & 7.50 & \text { Notes relating to physical features of material } \\ \text { EXTN } & 7.60 & \text { Extent (number of pages, pieces, etc.) } \\ \text { SIZE } & 7.70 & \text { Dimensions in centimeters (length } \times \text { width } \times \text { depth) } \\ \text { PHYC } & 7.80 & \text { Physical condition } \\ \text { LANG } & 8.00 & \text { Language code } \\ \text { LLCS } & 9.00 & \text { LCS code indicating which library has item } \\ \text { LCSH } & 10.00 & \text { Library of Congress Subject Headings } \\ \text { TOPC } & 11.00 & \text { General topic(s) or subject(s) } \\ \text { SHWN } & 12.00 & \text { Person(s), place }(s), \text { thing(s) illustrated } \\ \text { NOTE } & 13.00 & \text { Notes } \\ \text { RSTR } & 14.00 & \text { Restrictions } \\ \text { LINK } & 15.00 & \text { Linking record to larger collection to which item belongs } \\ \end{array}$

Library records (not available to public):

$\begin{array}{lll}\text { SACQ } & 16.00 & \text { Source of acquisition (name(s), address, phone) } \\ \text { ACDA } & 17.00 & \text { Accession date } \\ \text { MACQ } & 18.00 & \text { Method of acquisition: purchase, donation, gift, transfer, loan } \\ \text { PRPR } & 19.00 & \text { Purchase price } \\ \text { APVL } & 20.00 & \text { Appraisal value } \\ \text { ASVL } & 21.00 & \text { Assigned value } \\ \text { PRES } & 22.00 & \text { Preservation status indicator } \\ \text { ACTN } & 23.00 & \text { Action log (actions taken, dates, etc.) } \\ \text { DAFA } & 24.00 & \text { Date of future action(s) } \\ \text { RESR } & 25.00 & \text { Researcher(s) who have used material } \\ \text { RSCD } & 26.00 & \text { Record source code (person who created record) plus year, month, day }\end{array}$

FIGURE 2. Field abbreviations. 
It must be emphasized that all collections and significant subcollections will be represented on LCS and OCLC in cataloging records in the appropriate MARC format. The special collections automated finding aid is not intended to function as a library catalog, but more as an index. For example, the traditional American library cataloging concept of "main entry" will not be used. "Main entry" and "added entry" names will all be treated identically in the PERN field. (Names used as subjects will be put into separate fields.) The physical description fields will allow for expanded description of and access to both graphic items (such as an ambrotype) and support formats (such as a leather case). In this instance, both case and ambrotype would be described fully. Also, multiple sizes of posters for a film could be included in the same record, but posters of each size would be individually retrievable. Vocabulary control will be maintained in many of the physical description fields.

As part of the planning process, the committee attempted to learn of current projects which would be instructive as models. A literature search was done. Database documentation proved informative from two photography collections: the Center for Creative Photography, University of Arizona, and the Photography Collection, The Humanities Research Center, University of Texas at Austin. A review of museum-based data systems was also informative, and the Smithsonian Institution was contacted for information regarding its in-house system. Various visual resources librarians and other special collection librarians were consulted.

Discussion of the STAR system was initiated with the Getty Center for the History of Art and the Humanities which has used STAR for several years. In addition, an early prototype of the database was set up on Ingres at Ohio State.

Now that the plan for SCDB exists, the next step is to talk to vendors to determine whether or not any currently available software can implement it, before requests for funding can go forward. SCDB is still in the project definition stage and its final format is heavily dependent upon the software system chosen. Topping the list of products under consideration are BASIS, STAR, ARTIS and Ingres. We seek the reaction of our colleagues to the brief description of SCDB in this article and would be most grateful to receive any comments or suggestions for its improvement. Please send responses to Lucy Caswell, The Ohio State University, 242 West 18th Ave., Columbus OH 43210-1107 (614) 292-0538. We would be especially interested to know about other libraries which have created automated finding aids.

\section{Letter}

\section{BI for educators}

\section{To the Editor:}

The piece by the Bibliographic Instruction for Educators Committee of the EBSS section of ACRL (C\&RL News, April 1988, pp. 217-23) is seriously flawed, especially in the "Reference tools" section. Despite the disclaimer that "Inclusion in this list by no means indicates endorsement of the quality of information provided by the source" (to which one might well respond, "Why not?"), the first two books listed have drawn highly critical reviews since 1968. These are the Gourman Reports on graduate and undergraduate programs ( $3 \mathrm{rd}$ and 5 th editions, respectively).

Librarians in charge of selecting reference books might be excused for having missed the reviews in Personnel and Guidance Journal (May 1968); Journal of the Association of College Admissions Counselors (June 1968), reprinted in the Middle States Association Report (October 1968); the letter in the Journal of Education for Librarianship (Summer 1970); the full-page story in the Chronicle of Higher Education (May 8, 1978, as well as a letter, July 3,1978 , and another long story, February 15, 1984); and the 17-page definitive article in Change magazine (November/December 1984). But it is less easy to excuse overlooking the 9-page article in $R Q$ (Spring 1986).

If more need be said, a look at the new edition of Sheehy will disclose that the editors of that ALA publication declined to include the Gourman Reports because of serious questions about the validity of the compilations. To hand out the Gourman Reports in a public library to unsuspecting high school seniors is bad enough; to think of giving them to academic administrators, as the Committee recommends, is mind-numbing.

Perhaps one reason the Committee missed the recent critiques of Gourman's books is explained by the fact that the "Bibliography" section of its report contains no title dated later than 1984 .

The continuing uncritical use of the Gourman Reports calls into question standard library acquisition procedures. When a title is ordered without the backing of a faculty member or librarian, or a reputable review, does it then just land on the shelves without further examination? Do any libraries judge such books by more than their covers? Once a title is established on a library's shelves, are new editions ordered like a drug addict hungering for a new fix?-William R. Eshelman, The Press at the Camperdown Elm, Wooster, Ohio. 